useful. This discussion is pertinent not only to wildlife science but to all spheres of enquiry.

Lewis does not mince his words. For instance, he observes that neither Raghavendra Gadagkar of the Centre for Ecological Sciences in Bangalore nor US ecologists such as E. O. Wilson "are willing to abandon theoretical ecology to take up taxonomy though. Gadagkar encourages students to do so, and Wilson ecologists of the developing world to do the same. Neither will do it himself." And while talking about differences between India and the West, he writes that villages in India, "even those who lose crops and occasionally relatives, have existed in close contact with dangerous wildlife for centuries without driving those animals to extinction. Before the British there was no evidence of Indian 'predator elimination hunts' in the style of the Texas rattlesnake drives or the turn-of-the-century wolf bounties in the United States, aimed at the eradication of every member of a given species." There is something irresistibly refreshing about Lewis's willingness to speak his mind.

In keeping with his seemingly earnest desire to faithfully reproduce all his findings, all of his conversations (or rather, the relevant sections of them) seem to be recorded verbatim. The book is thus peppered with quotes in 'Hinglish', and misplaced modifiers, fractured sentence construction and other endearing linguistic idiosyncrasies are rife.

Despite its scholarly character, this book is user-friendly for lay-readers, thanks in no small measure to the author's superb storytelling ability. The more informed reader might skip over a couple of pages here and there with a 'been there, done that' shrug, but I suspect that few ecologists are privy to the intricate history of their chosen field of work. The book thus serves to round out their education by providing a historical and philosophical perspective.

Deepak Apte is head of the Conservation Department, Bombay Natural History Society, Hornbill House, S. B. Singh Road,

Mumbai 400 023, India.

\section{Erratum}

We apologize to Gordon M. Burghardt for misspelling his name in the recent review of his book The Genesis of Animal Play (Nature 434, 273-274; 2005).

\title{
Science and superstition
}

\section{Thomas Heatherwick's sculpture for the Wellcome Trust's new building in London.}

\section{Martin Kemp}

Foyer sculptures - those big lumps of arty stuff commissioned to hang or stand in the entrance spaces of large modern buildings - don't tend to occupy a high rank in the pantheon of contemporary art. There is often an inverse relationship between the size of the object and the attention it commands from those who come and go. Generally decided by committees, which are inherently uncreative, these sculptures typically occupy an unsatisfying middle ground: just modern enough to seem adventurous without imposing themselves demandingly on the viewer.

In this context, it is good to see that the massive piece commissioned from Thomas Heatherwick, which adorns a seven-story space in the Wellcome Trust's new headquarters in London (designed by Hopkins Architects), is a technical, visual and conceptual tour de force.

The statistics are impressive enough in themselves: there are almost 150,000 glass spheres; 26,732 stainless steel wires, $0.5 \mathrm{~mm}$ in diameter, and the same number of springs; the sculpture is nearly 30 metres in height; and it has a total weight of 14 tonnes. Needless to say, such a work is not the product of an archetypal artist working in romantic isolation in a studio-garret. The teamwork required is akin to that in the workshop of a major Renaissance artist-engineer.

Even more impressive, for those who enter, leave and pass by the building, are the beguiling visual effects and complex associations embedded within the sculpture. Each of the glass beads is composed of two hemispheres surrounding a piece of dichroic film that generates a range of floating effects, from clear to turquoise, pink, green, yellow, violet and orange. The glass and film together ensure that the visual impact is continually transformed as the light changes and the spectator moves through the space.

The overall form is the result of a self-organizing process. Heatherwick and his team experimented with a range of viscous molten substances, dropping them into water and watching them solidify in shapes that are unpredictable yet observe certain material parameters. Such configurations, suggestive of organic entities, were among those considered by D'Arcy Thompson in his great 1917 book, On Growth and Form. Metal proved most amenable, and, after some 400 tests, a small piece of solidified white metal was selected. This small model was then translated digitally by a screen matrix into an overall configuration of suspended beads.

The work that arose from this process does not have one single meaning. The parameters of interpretation are set in part by its presence in the headquarters of one of the world's major medical research charities. Parallels of the structure with molecular models are almost inescapable.

The German title, Bleigiessen, has strong associations with health. 'Lead-guessing' is a New Year's Eve ritual in central Europe. Molten lead is poured into water and the resulting shapes are divined as signalling a person's fortune. Yet Heatherwick did not intend this as a meaning from the beginning. It was only late in the process of design that he learnt about 'lead-pouring' from his German grandmother.

The end result is that the inherent unpredictability of the process of cooling molten metal in water belongs simultaneously to modern science and to folk intuitions about the vagaries of fortune that govern all our lives. Henry Wellcome, founder of the trust, would have been delighted by this unanticipated conjunction of modern scientific knowledge with the superstitions behind traditional customs.

Martin Kemp is professor of the history of art at the University of Oxford, Oxford OX1 1PT, UK, and co-director of Wallace Kemp Artakt.

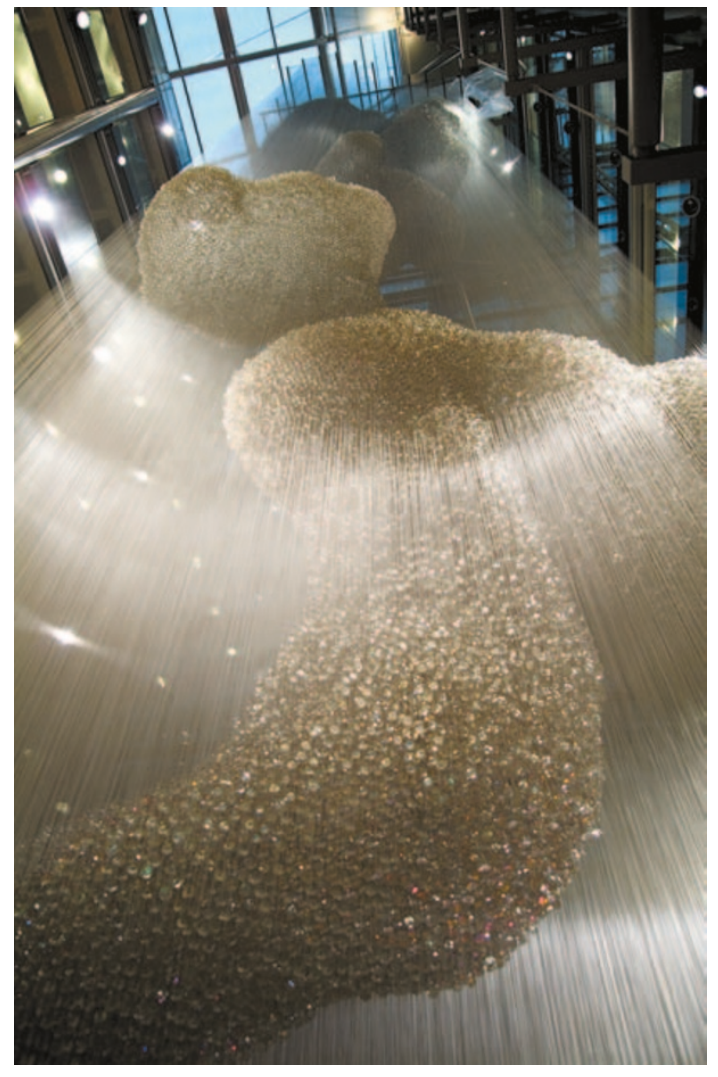

